\title{
Immobilization of simulated radioactive fluoride waste in phosphate glass
}

\author{
Yaping Sun ${ }^{1,2}$, Xiaobin Xia ${ }^{*}$, Yanbo Qiao ${ }^{1}$, Liangmao Bao ${ }^{1}$, Hongjun Ma ${ }^{1}$, Xueyang Liu ${ }^{1}$ \\ and Zhenghua Qian ${ }^{1}$
}

\begin{abstract}
Radioactive alkali fluoride salts are generated during the operation of molten salt reactors (MSRs) and reprocessing of their spent fuel, and appear in the form of fluidity granule, or powder. In order to prevent the radionuclides from being released into the environment (especially, via exposure to water), it is necessary to develop a new technology for the temporary storage or final disposal of wastes containing radioactive fluorides. The immobilization of alkali fluoride wastes in phosphate glasses has been proposed. In this study, iron phosphate (IP) glasses and sodium aluminophosphate ( $\mathrm{NaAlP})$ glasses were evaluated for the immobilization of simulated radioactive fluoride wastes. IP and NaAlP glass matrixes were mixed with simulated wastes and reacted in air at temperatures in the range of $950-1200^{\circ} \mathrm{C}$. A high waste loading was obtained in the experiment. The properties of the waste forms were characterized by $\mathrm{X}$-ray diffraction and Raman spectroscopy. The latter indicated that IP glass contains less $Q^{2}$ without $Q^{3}$ ( 2 and 3 represent the number of bridging oxygens on a $\mathrm{PO}_{4}$ tetrahedron), and it is concluded that IP glass is more stable than NaAlP glass. Leaching tests were performed in deionized water by using the product consistency test A (PCT-A method), and the result shows that the leaching resistance of IP waste forms is better than that of NaAlP waste forms. This study demonstrates the potential of IP glass for the stabilization and immobilization of radioactive fluoride wastes from MSRs.
\end{abstract}

Keywords: radioactive waste, alkali fluoride, iron phosphate glass, sodium aluminophosphate glass

\section{INTRODUCTION}

Molten salt reactor (MSR) is the sole liquid-fuel reactor among the six candidate reactors of the Generation IV advanced nuclear energy systems, and utilizes liquid molten fluoride salts simultaneously as fuel and coolant $[1,2]$. The major distinguishing characteristic of an MSR with a water reactor is that its fuel containing fissile cations dissolves in low-viscosity, high-boiling fluoride salt mixtures. Under the shutdown condition, the salts are drained out to storage casks. Considering the high radioactivity levels of the fission and activation products, attention should be paid to the fuel cycle work. A fluoride volatility method has been developed to separate uranium and other fission products from fluoride salt solutions, but an amount of radioactive fluoride wastes is generated in the process [3]. Many such fluorides are in the form of fluidity granule, or powder, and are highly soluble in water. Therefore, it is necessary to program an additional safety barrier to prevent the radionuclides from being released into the environment, especially from exposure to water.

Based on the experience with the molten salt reactor experiment (MSRE), a previous study considered that the interim storage of the residual salts was the only realistic option available at the time [4]. This solution does provide adequate protection for human health and the environment, but eventually an ultimate disposition must be identified to end the cost of perpetual care and monitoring. Moreover, other options have been proposed for the final disposition of the residual salts. However, one does not know at this time which options will be available in the future, and choices cannot be made until more information is available [3]. As proposed by the Oak Ridge National Laboratory (ORNL), an alternate approach to stabilizing the fluoride salts is to convert the material from a fluoride to an oxide by using a waste calcining facility or a glass material oxidation and dissolution system (GMODS). Another possibility is the immobilization of the fluorides in glass, including

\footnotetext{
${ }^{1}$ Shanghai Institute of Applied Physics, Chinese Academy of Sciences, Shanghai 201800, China

${ }^{2}$ University of Chinese Academy of Sciences, Beijing 100049, China

* Corresponding author (email: xiaxiaobin@sinap.ac.cn)
} 
borosilicate glass or phosphate glass (mineral), because it reduces the potential for migration or dispersion of contaminants, including radionuclides. Although borosilicate glass has been under investigation in great detail and developed for embedding high level wastes (HLWs) [5,6], it cannot accommodate a large amount of fluorides owing to the low fluoride solubility in the host $[7,8]$. For example, the acceptability determination for process control of the defense waste processing facility (DWPF) limits the fluoride content in the DWPF feed to $1 \mathrm{~g} \mathrm{NaF}$ per $100 \mathrm{~g}$ glass [3].

The restricted solubility of compounds, such as $\mathrm{P}_{2} \mathrm{O}_{5}$, sulfates, halides, and actinides, in silicate melts has encouraged waste-form designers to once again judge the potential of $\mathrm{P}_{2} \mathrm{O}_{5}$-based glass systems as host matrices [9]. Many studies on "composition-property-structure correlations" in various phosphate-based glasses and waste glasses have already been conducted, and some of these phosphate glasses are considered very promising, as they are chemically durable, thermally stable, and can be processed at moderate temperatures. Iron phosphate (IP) glasses were proposed for the immobilization of $\mathrm{CsCl}$ and $\mathrm{SrF}_{2}$ extracted from HLW tank sludge, and up to $26 \mathrm{~mol} \%$ $\mathrm{CsCl}, 31 \mathrm{~mol} \% \mathrm{SrF}_{2}$, and a $34 \mathrm{~mol} \%$ mixture of $\mathrm{CsCl}$ and $\mathrm{SrF}_{2}$ were combined respectively [10]. Siemer processed fluoride wastes by volatilization/separation of the bulk of the fluorine, and vitrified its cationic components (mostly alkali metals and fission products (FPs)) to an iron phosphate glass waste form, obtaining a much higher effective waste loading $[11,12]$. Sodium aluminophosphate (NaAlP) glasses had been selected as the glass matrix in the former Soviet Union [13] and developed at the Institute of Physical Chemistry of the Russian Academy of Sciences [14].

If any of the geologic disposal alternatives prove technically and programmatically implementable, every reasonable effort should be made to implement that alternative. The following considerations, outlining a cautious stepwise strategy, were taken into account in the development of a preferred approach to the immobilization of alkali fluorides in this paper. IP and NaAlP glasses were proposed as glass matrixes to immobilize alkali fluorides and the feasibility of the formulations $\left(40 \% \mathrm{Fe}_{2} \mathrm{O}_{3}-60 \% \mathrm{P}_{2} \mathrm{O}_{5}\right.$ and $\mathrm{NaAlP}$ formula from Donald et al. [8]) was studied. The potential waste loading was investigated and the influence of the additives (e.g., $\mathrm{Fe}_{2} \mathrm{O}_{3}, \mathrm{~B}_{2} \mathrm{O}_{3}, \mathrm{CaO}$ ) on the properties of waste forms was also characterized. Leaching tests were then performed in deionized water by using the product consistency test A (PCT-A method) [15], which simulates the extreme conditions (i.e., moist air and high temperature) of underground repositories.

\section{EXPERIMENT S}

\section{Sample preparation}

The content of the waste is important because the characteristics of both the waste form and the process are dominated by its major components. One type of radioactive waste generated by the fluoride volatility method is alkali fluorides. Table 1 (from Table 7 in Ref. [16]) lists the sources and quantities of the constituents generated by a 1.0 GW (electric) molten salt breeder reactor (MSBR) $[11,16]$. It is noteworthy that the waste consists primarily of the fluoride salts of $\mathrm{Li}, \mathrm{K}$, and $\mathrm{Na}$, rather than FPs. Even though the content of radioactive elements in the waste salts is very low, the salts may be legally considered an HLW because they derive from the first stream in the processing of irradiated fuel [17].

It can be assumed that the alkali fluoride wastes generated by other MSRs are similar to those presented in Table 1 , and our simulated non-radioactive waste consists of 18.8 mol\% LiF, $23.8 \mathrm{~mol} \% \mathrm{NaF}, 0.1 \mathrm{~mol} \% \mathrm{MgF}_{2}$, $57 \mathrm{~mol} \% \mathrm{KF}$ and $0.3 \mathrm{~mol} \% \mathrm{FP}\left(0.125 \mathrm{CsF}, 0.125 \mathrm{SrF}_{2}, 0.75 \mathrm{CeO}_{2}\right)$. In this paper, $\mathrm{MF}_{n}$ is used to represent the mixed fluorides of the simulated waste.

Glasses with the compositions listed in Tables 2 and 3 were prepared by melting a reagent-grade mixture of ammonium dihydrogen phosphate $\left(\mathrm{NH}_{4} \mathrm{H}_{2} \mathrm{PO}_{4}\right)$, iron oxide $\left(\mathrm{Fe}_{2} \mathrm{O}_{3}\right)$, sodium hydroxide $(\mathrm{NaOH})$, aluminum oxide $\left(\mathrm{Al}_{2} \mathrm{O}_{3}\right)$, and the raw materials of non-radioactive simulated waste. Well-mixed glass powders (no fluoride) were first preheated to $300^{\circ} \mathrm{C}$ (with a heating rate of $10^{\circ} \mathrm{C} \mathrm{min}^{-1}$ ) in an alumina crucible and maintained at this temperature

Table 1 MSBR salt wastes

\begin{tabular}{ccc}
\hline Constituent & Source & $\mathrm{g} \mathrm{mol} \mathrm{yr}^{-1}$ \\
\hline $\mathrm{LiF}$ & Discarded fuel salt (still bottoms) & $5.6 \times 10^{4}$ \\
$\mathrm{NaF}$ & Adsorbant & $7.1 \times 10^{4}$ \\
$\mathrm{MgF}_{2}$ & Adsorbant & $3.1 \times 10^{3}$ \\
$\mathrm{KF}$ & Derived from the KOH mostly used for off-gas scrubbing & $1.7 \times 10^{5}$ \\
$\mathrm{PF}$ & Miscellaneous fission products in the above wastes & $7.4 \times 10^{3}$ \\
\hline
\end{tabular}


Table 2 Composition of iron phosphate-based glasses (mol\%)

\begin{tabular}{cccccc}
\hline & $\mathrm{P}_{2} \mathrm{O}_{5}$ & $\mathrm{Fe}_{2} \mathrm{O}_{3}$ & $\mathrm{~B}_{2} \mathrm{O}_{3}$ & $\mathrm{CaO}$ & $\mathrm{MF}_{n}$ \\
\hline IP-F1 & 52.4 & 34.9 & $/$ & $/$ & 12.7 \\
IP-F2 & 45.8 & 30.6 & $/$ & $/$ & 23.6 \\
IP-F3 & 40.1 & 26.8 & $/$ & $/$ & 33.1 \\
IP-F4 & 37.4 & 25.0 & $/$ & $/$ & 37.6 \\
IP-F5 & 33.9 & 22.6 & $/$ & $/$ & 43.5 \\
B1-IP & 45.4 & 22.7 & 7.6 & $/$ & 24.3 \\
B2-IP & 38.3 & 25.3 & 13.0 & $/$ & 23.4 \\
Ca1-IP & 42.5 & 27.5 & $/$ & 3.7 & 26.3 \\
Ca2-IP & 38.1 & 24.3 & $/$ & 6.9 & 30.7 \\
\hline
\end{tabular}

for $3 \mathrm{~h}$ to evaporate ammonia and water in the batches. The batches were then melted in air at $1000-1250^{\circ} \mathrm{C}$ for $30 \mathrm{~min}$ and the fused glass was poured into a steel mold. Next, the powders grinded from the glasses were well-mixed with the fluorides, the amount of which ranged from 10 to 50 mol\%. Finally, the mixtures were remelted at $950-1000^{\circ} \mathrm{C}$ to obtain homogeneous samples.

The experiments aimed at establishing the maximum amount of fluoride that could be incorporated into these glasses. The melting schedule was adjusted according to the viscosity of the melt and the observed volatility.

\section{Sample characterization}

The identification of the crystalline phases present in the glass samples was performed using X-ray diffraction (XRD, D8 advance, Bruker, Germany). The structure of the glass samples was measured by a Raman spectrometer (HR800, Renishaw, England) coupled with an optical microscope by using a laser of wavelength $532 \mathrm{~nm}$. The composition of the leachates was measured by the inductively coupled plasma optical emission spectrometry. The concentrations of $\mathrm{F}$ ions were monitored by a fluorine-ion electrode and the $\mathrm{pH}$ values of the leachates were also measured.

\section{Leaching resistance}

The product of any competent radioactive waste forms should be highly resistant to corrosion against water and not readily dispersible (i.e., monolithic, rather than "dusty"). Leaching experiments were conducted following the PCT-A method to evaluate the leaching resistance of the waste forms. The glass powder (sizes ranging from 75 to $150 \mu \mathrm{m}$ ) was mixed with distilled water at a ratio of $10 \mathrm{~mL} \mathrm{~g}^{-1}$, and held at $90^{\circ} \mathrm{C}$ for 7 days in a stainless-steel vessel. The leaching data were converted to leaching ability units $\left(\mathrm{g} \mathrm{m}^{-2}\right)$ by using the formula:

$$
L=C_{i} V / f_{i} A,
$$

where $C_{i}$ is the concentration of species $i$ in the leachate in $\mathrm{g} \mathrm{mL}^{-1}, V$ is the volume of the leachate in $\mathrm{mL}, f_{i}$ is the initial fraction of species $i$ in the solid, and $A$ is the surface area of the solid in $\mathrm{m}^{2}$. A typical density of $3.0 \mathrm{~g} \mathrm{~cm}^{-3}$ was assumed for glasses and the surface area per gram of waste form was then calculated as $1.79 \times 10^{-2} \mathrm{~m}^{2}$.

\section{RESULTS AND DISCUSSION}

\section{X-ray diffraction}

Fig. 1a presents the XRD patterns of the $x \mathrm{MF}_{n^{-}}(100-x)$ IP glass samples with $x=37.6 \mathrm{~mol} \%, 43.5 \mathrm{~mol} \%$, respectively. The compositions containing up to $37.6 \mathrm{~mol} \%$ of $\mathrm{MF}_{n}$ form glasses, and no crystalline phases are detected by XRD. For the samples with $\mathrm{MF}_{n}$ ratios $\geq 43.5 \mathrm{~mol} \%$, the crystalline phases are obviously detected. The major crystalline phase has been identified as $\mathrm{KFeP}_{2} \mathrm{O}_{5}$ (36-1457).

Fig. $1 \mathrm{~b}$ presents the XRD patterns of the $x \mathrm{MF}_{n}-(100-x)$ NaAlP glass samples with $x=37.8 \mathrm{~mol} \%, 48.6 \mathrm{~mol} \%$, respectively. For the samples with $\mathrm{MF}_{n}$ ratios $\geq 48.6 \mathrm{~mol} \%$, the crystalline phases are detected and the structure is not easy to identify. Fig. 1 reveals that both IP and NaAlP glass own a higher effective waste loading of fluorides than borosilicate glasses.

\section{Raman spectroscopy}

The short range order (SRO) of phosphate can be described by considering the compositional dependence of the frac-

Table 3 Composition of sodium aluminumphosphate-based glasses (mol\%)

\begin{tabular}{|c|c|c|c|c|c|c|}
\hline & $\mathrm{P}_{2} \mathrm{O}_{5}$ & $\mathrm{Al}_{2} \mathrm{O}_{3}$ & $\mathrm{Na}_{2} \mathrm{O}$ & $\mathrm{Fe}_{2} \mathrm{O}_{3}$ & $\mathrm{CaO}$ & $\mathrm{MF}_{n}$ \\
\hline NaAlP-F1 & 34.4 & 16.8 & 35.3 & 1 & 1 & 13.6 \\
\hline NaAlP-F2 & 29.4 & 14.3 & 30.1 & l & I & 26.2 \\
\hline NaAlP-F3 & 24.8 & 12.1 & 25.4 & I & l & 37.8 \\
\hline NaAlP-F4 & 20.5 & 10.0 & 21.0 & I & I & 48.6 \\
\hline Fe1-NaAlP & 29.9 & 13.4 & 28.0 & 2.6 & I & 26.2 \\
\hline Fe2-NaAlP & 30.8 & 11.7 & 24.5 & 6.8 & l & 26.2 \\
\hline Ca1-NaAlP & 30.7 & 14.6 & 24.7 & I & 6.9 & 22.9 \\
\hline Ca2-NaAlP-F1 & 28.7 & 12.5 & 26.0 & I & 7.7 & 25.0 \\
\hline Ca2-NaAlP-F2 & 22.9 & 10.0 & 20.8 & l & 6.2 & 40.0 \\
\hline
\end{tabular}



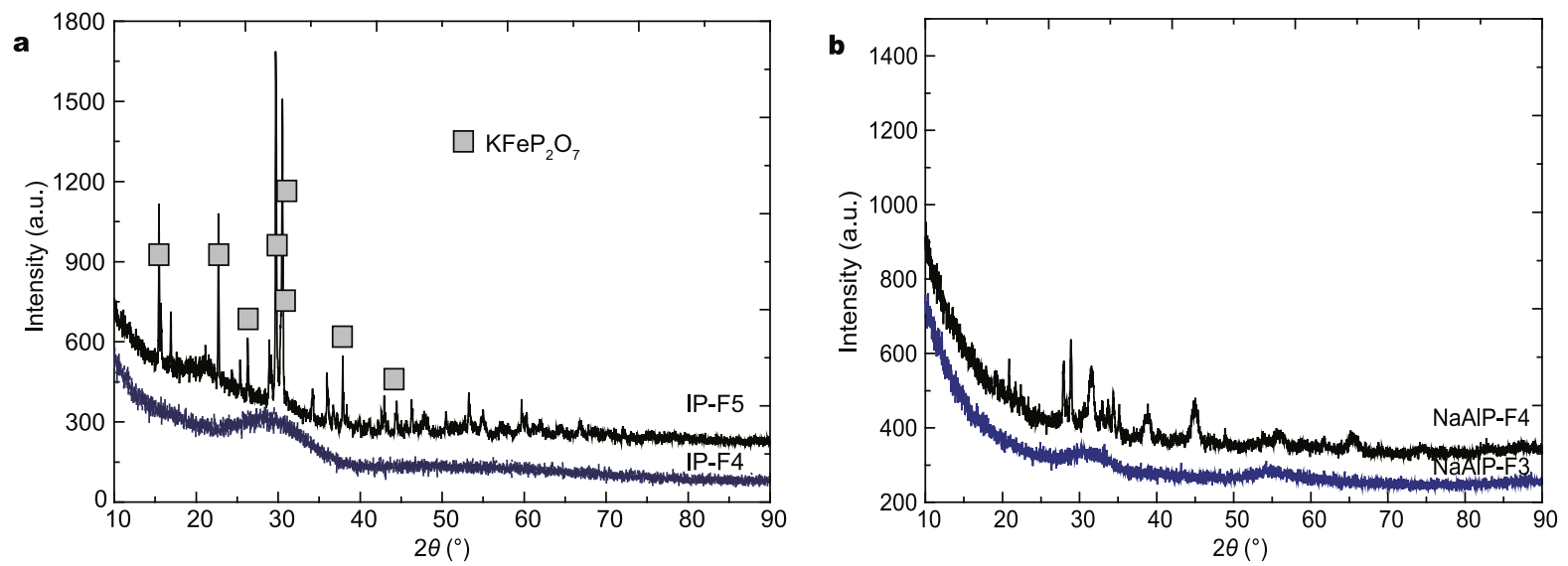

Figure 1 XRD patterns of (a) $x \mathrm{MF}_{n}(100-x)$ IP and (b) $x \mathrm{MF}_{n^{-}}(100-x) \mathrm{NaAlP}$ glass samples.

tions of different tetrahedral phosphate species $Q^{n}(n=0$, 1,2 , and 3), where the superscript " $n$ " represents the number of bridging oxygens (BOs) on a $\mathrm{PO}_{4}$ tetrahedron. Phosphate glasses can be made with a range of structures, from a cross-linked network of $Q^{3}$-tetrahedra (vitreous $\mathrm{P}_{2} \mathrm{O}_{5}$ ), to polymer-like metaphosphate chains of $Q^{2}$-tetrahedra, to "invert" glasses based on small pyro- $\left(Q^{1}\right)$ and orthophosphate $\left(Q^{0}\right)$ anions. Among them, $Q^{3}$ and $Q^{2}$ are somewhat unstable because of the high BOs [18]. Raman spectra of the fluoride-containing glasses of IP-F $(3,4)$ and NaAlP$F(2,3)$ are presented in Fig. 2. The peaks in the spectra can be assigned to their vibrational mode according to known frequencies from IP glasses reported in Refs. [18-20], and NaAlP glasses in Refs. [21-23], some of which are summarized in Table 4.

The most intense peaks in each spectrum are located from $\sim 900$ to $\sim 1150 \mathrm{~cm}^{-1}$. The bands between 700 and $800 \mathrm{~cm}^{-1}$ are related to the symmetric $\mathrm{P}-\mathrm{O}-\mathrm{P}$ stretching modes associated with linkages to a $Q^{1}$-tetrahedra. The peak from $\sim 900$ to $\sim 1010 \mathrm{~cm}^{-1}$ can be assigned to the symmetric stretch of a non-bridging oxygen (NBO) on a $Q^{0}$-tetrahedron, the $\left(\mathrm{PO}_{4}\right)_{\text {sym }}$ mode. The peak from $\sim 1010$ to $\sim 1100 \mathrm{~cm}^{-1}$ can be attributed to the symmetric stretch

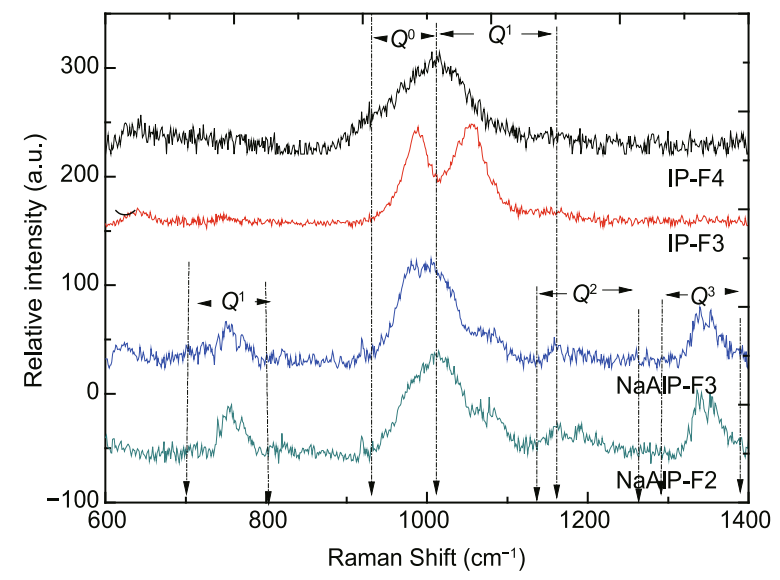

Figure 2 Raman spectra of $x \mathrm{MF}_{n}(100-x)$ IP and $x \mathrm{MF}_{n}-(100-x) \mathrm{NaAlP}$ glass samples.

Table 4 Summary of Raman frequency ranges from iron [18], sodium [22], sodium-alumino [23], and calcium [24] phosphate

\begin{tabular}{cccc}
\hline Vibrational mode & \multicolumn{3}{c}{ Band position $\left(\mathrm{cm}^{-1}\right)$} \\
\cline { 2 - 4 } & $\mathrm{Fe}_{2} \mathrm{O}_{3}-\mathrm{P}_{2} \mathrm{O}_{5}$ & $x \mathrm{Na}_{2} \mathrm{O}-(1-x) \mathrm{P}_{2} \mathrm{O}_{5}$ & $40 \mathrm{Na}_{2} \mathrm{O}_{-10 \mathrm{Al}_{2} \mathrm{O}_{3}-x \mathrm{TiO}_{2}-(50-x) \mathrm{P}_{2} \mathrm{O}_{5}}$ \\
\hline $\mathrm{P}-\mathrm{O}-\mathrm{P}$ symmetric stretch $\left(Q^{3}\right)$ & $/$ & 640 & 693,737 \\
$\mathrm{P}-\mathrm{O}-\mathrm{P}$ symmetric stretch $\left(Q^{2}\right)$ & $680-720$ & 690 & 748 \\
$\mathrm{P}-\mathrm{O}-\mathrm{P}$ symmetric stretch $\left(Q^{1}\right)$ & $720-780$ & 810,910 & $/$ \\
$\mathrm{PO}_{4}$ symmetric stretch $\left(Q^{0}\right)$ & $990-1010$ & $927-950$ & $1010-1050$ \\
$\mathrm{PO}_{3}$ symmetric stretch $\left(Q^{1}\right)$ & $1030-1100$ & $1037-1064$ & 1100 \\
$\mathrm{PO}_{3}$ asymmetric stretch $\left(Q^{1}\right)$ & $\sim 1200$ & 1170 & $1147-1160$ \\
$\mathrm{PO}_{2}$ symmetric stretch $\left(Q^{2}\right)$ & $1050-1220$ & $1105-1121,1190-1195$ & $1174-1277$ \\
$\mathrm{PO}_{2}$ asymmetric stretch $\left(Q^{2}\right)$ & $1250-1310$ & $1207-1228,1269-1287$ & 1104 \\
$(\mathrm{P}=\mathrm{O})$ sym stretch $\left(Q^{3}\right)$ & $/$ & $1280-1390$ & $/$ \\
\hline
\end{tabular}


of a $\mathrm{NBO}$ on a $Q^{1}$-tetrahedron, the $\left(\mathrm{PO}_{3}\right)_{\text {sym }}$ mode. The higher frequency $\left(>1100 \mathrm{~cm}^{-1}\right)$ shoulders evident in each spectrum could be caused by asymmetric $\mathrm{PO}_{3}$ modes associated with the $Q^{1}$-tetrahedra, but could alternatively arise from symmetric $\mathrm{PO}_{2}$-stretching modes associated with a $Q^{2}$-tetrahedra.

The content of each $Q^{n}$ in the glass depended on the species of network formings (e.g., $\mathrm{P}_{2} \mathrm{O}_{5}$ ), network intermediates (e.g., $\mathrm{Fe}_{2} \mathrm{O}_{3}, \mathrm{Al}_{2} \mathrm{O}_{3}$ ), network modifiers (e.g., $\mathrm{M}_{2} \mathrm{O}$ ), and even on their ratios and the resulting $\mathrm{O} / \mathrm{P}$ ratio as set by the glass composition [18]. Compared with binary sodium phosphate glass $\left(\mathrm{Na}_{2} \mathrm{O}-\mathrm{P}_{2} \mathrm{O}_{5}\right.$, see Table 4$)$, the Raman spectra of IP samples (IP-F3, IP-F4) do not show long chain phosphate structures $\left(Q^{2}\right.$ or $Q^{3}$ units), which is similar to $\mathrm{CaO}-\mathrm{P}_{2} \mathrm{O}_{5}$ as observed by Kasuga and Abe [24]. The depolymerization of the phosphate networks is mainly caused by $\mathrm{Fe}-\mathrm{O}-\mathrm{P}$ bonds replacing $\mathrm{P}-\mathrm{O}-\mathrm{P}$ bonds in these glasses, similar to $\mathrm{Fe}_{2} \mathrm{O}_{3}-\mathrm{P}_{2} \mathrm{O}_{5}$ in Table $4[10,18]$; at the same time, a mass of $\mathrm{R}^{+}$(alkali ions) also results in the creation of NBOs at the expense of BOs and, therefore, lower $n$ in $Q^{n}$, as described by Equation (2) [25],

$$
2 Q^{n}+\mathrm{R}_{2} \mathrm{O} \rightarrow 2 Q^{n-1} .
$$

Thus, the asymmetric bridging oxygen content increases with the addition of $\mathrm{MF}_{n}$. Moreover, fluorine can replace oxygen in different $Q^{n}$ species and causes a slight reduction in the glass network connectivity [26,27], but this decrease is small and depends on the atomic ratio of oxygen to phosphorus $(\mathrm{O} / \mathrm{P})$.

For NaAlP samples, it is worth noting that, a small amount of $Q^{3}$ units still exists in the glasses, with the exception of $Q^{1}$ and $Q^{0}$ units. The content is lower than that of $\mathrm{Na}_{2} \mathrm{O}-\mathrm{P}_{2} \mathrm{O}_{5}$, and higher than that of $40 \mathrm{Na}_{2} \mathrm{O}-10 \mathrm{Al}_{2} \mathrm{O}_{3}-x \mathrm{TiO}_{2}-(50-x) \mathrm{P}_{2} \mathrm{O}_{5}$ (see Table 4). For the latter, it is not clear whether the asymmetric $\mathrm{BO}$ content increases with the addition of $\mathrm{MF}_{n}$ by simply consulting the content of $Q^{3}$ units, because the constituent ratios of $\mathrm{Na}_{2} \mathrm{O}-\mathrm{Al}_{2} \mathrm{O}_{3}-\mathrm{P}_{2} \mathrm{O}_{5}$ is different in Ref. [23] and in the NaAlP samples.

\section{Leaching resistance}

As shown in Table 5, the leaching data for the IP samples indicates that all normalized ion releases are $\leq 2 \mathrm{~g} \mathrm{~m}^{-2}$ in the test period, namely, $<0.3 \mathrm{~g} \mathrm{~m}^{-2} \mathrm{day}^{-1}$, which meets the requirement of EJ 1186-2005 $\left(<1 \mathrm{~g} \mathrm{~m}^{-2}\right.$ day $\left.^{-1}\right)$ [28]. The quantity released from the IP waste forms did not change substantially when $\mathrm{B}_{2} \mathrm{O}_{3}$ (for B1-IP-F and B2-IP-F) or $\mathrm{CaO}$ (for Ca1-IP-F and Ca2-IP-F) were added.

There are large amounts of $\mathrm{Fe}_{2} \mathrm{O}_{3}$ in these glasses, but very little iron was detected in the leachates. This result is consistent with that reported by Mesko et al. [10]. The good leaching durability is primarily caused by the presence of strong, hydration-resistant $\mathrm{Fe}-\mathrm{O}-\mathrm{P}$ bonds in these glasses [10,29]. Although the release of the alkali metal cations was highest for the IP glasses, their networks remain largely insensitive to the addition of cations and can solubilize them in high quantity without sacrificing leaching resistance, which is also consistent with that reported by Bingham et al. [19].

NaAlP glasses were used for comparison with IP glasses in the leaching resistance studies. As shown in Table 6, the release of $\mathrm{Na}$ and $\mathrm{K}$ from $\mathrm{NaAlP}$ glasses is quite high, which is associated with high $\mathrm{Na}$ content from the matrix itself and alkalis from $\mathrm{MF}_{n}$. As reported by Liao et al. [30], when the molar ratio of $\mathrm{Na}_{2} \mathrm{O} / \mathrm{Al}_{2} \mathrm{O}_{3}>2$, the structure of the glass waste forms becomes poor; the $\mathrm{Al}$ content is very low, causing a decrease in $\left[\mathrm{AlO}_{4}\right]$ content [31], which plays an important role in the network density at this condition, and excessive alkali ions have the effect of breaking networks in the structure. In addition, the low structure quality may be related to the existence of $Q^{3}$ units, where three of the oxygens are bridging $(\mathrm{P}-\mathrm{O}-\mathrm{P})$ and one is non-bridging $(\mathrm{P}=\mathrm{O})$.

Table 5 Normalized elemental mass release from iron phosphate waste forms $\left(\mathrm{g} \mathrm{m}^{-2}\right)$

\begin{tabular}{|c|c|c|c|c|c|c|c|c|c|c|c|c|}
\hline & $\mathrm{F}$ & $\mathrm{Li}$ & $\mathrm{Na}$ & $\mathrm{K}$ & $\mathrm{Mg}$ & $\mathrm{Ca}$ & $\mathrm{Sr}$ & B & $\mathrm{P}$ & $\mathrm{Ce}$ & $\mathrm{Fe}$ & $\mathrm{PH}$ \\
\hline IP-F1 & 0.02 & 0.31 & 0.48 & 0.07 & 0.24 & 1 & 0 & 1 & 0.01 & 0 & 0 & 7.46 \\
\hline IP-F2 & 0.06 & 0.26 & 0.44 & 0.07 & 0.12 & I & 0 & I & 0.02 & 0 & 0 & 7.08 \\
\hline IP-F3 & 0.02 & 0.27 & 0.06 & 0.02 & 0.08 & I & 0 & I & 0.01 & 0 & 0 & 7.12 \\
\hline IP-F4 & 0.01 & 0.26 & 1.92 & 0.39 & l & I & 1 & I & 0.14 & 0 & 0 & 7.01 \\
\hline IP-F5 & 0.30 & 0.35 & 0.96 & 0.27 & l & I & I & l & 0.12 & 0 & 0 & 6.45 \\
\hline B1-IP-F & 0.22 & 0.49 & 1.83 & 0.25 & 0.12 & I & 0 & 0.01 & 0.05 & 0.01 & 0 & 7.15 \\
\hline B2-IP-F & 0.03 & 0.22 & 0.39 & 0.05 & 0.11 & I & 0 & 0.01 & 0.02 & 0 & 0 & 7.07 \\
\hline Ca1-IP-F & 0.01 & 0.25 & 0.16 & 0.08 & 0.31 & 0.02 & 0 & I & 0.01 & 0 & 0 & 6.6 \\
\hline Ca2-IP-F & 0.00 & 0.12 & 0.19 & 0.02 & 0.21 & 0.02 & 0 & l & 0.01 & 0 & 0 & 7.19 \\
\hline
\end{tabular}


Table 6 Normalized elemental mass release from sodium aluminophosphate waste forms $\left(\mathrm{g} \mathrm{m}^{-2}\right)$

\begin{tabular}{|c|c|c|c|c|c|c|c|c|c|c|c|c|}
\hline & $\mathrm{F}$ & $\mathrm{Li}$ & $\mathrm{Na}$ & $\mathrm{K}$ & $\mathrm{Mg}$ & $\mathrm{Ca}$ & $\mathrm{Sr}$ & $\mathrm{Al}$ & $\mathrm{P}$ & $\mathrm{Ce}$ & $\mathrm{Fe}$ & $\mathrm{PH}$ \\
\hline NaAlP-F1 & 0.20 & 0.01 & 24.99 & 14.46 & 0 & I & 0 & 0.01 & 0.01 & 0.01 & 0 & 10.41 \\
\hline NaAlP-F2 & 4.64 & 0.06 & 145.31 & 124.43 & 0 & I & 0 & 0 & 0.05 & 0.01 & 0 & 8.38 \\
\hline NaAlP-F3 & 10.25 & 0.12 & 328.15 & 32.34 & 0 & l & 0 & 0 & 0.11 & 0 & 0 & 9.54 \\
\hline NaAlP-F4 & 2.97 & 0.05 & 264.82 & 43.58 & 0 & I & 0 & 0 & 0.26 & 0 & 0 & 9.44 \\
\hline Fe1-NaAlP-F & 0.30 & 0.01 & 23.21 & 9.20 & 0 & l & 0 & 0.01 & 0 & 0.01 & 0 & 10.51 \\
\hline Ca1-NaAlP-F & 0.11 & 0.04 & 0.71 & 0.10 & 0.36 & 0.01 & 0 & 0.18 & 0.22 & 0.02 & 0 & 9.60 \\
\hline Ca2-NaAlP-F2 & 0.22 & 0.22 & 0.54 & 0.39 & 12.47 & 0.01 & 99.89 & 0.18 & 0.22 & 0 & 0 & 9.94 \\
\hline Ca2-NaAlP-F3 & 7.06 & 16.8 & 24.52 & 25.91 & 8.90 & 0.01 & 56.97 & 0.91 & 15.73 & 0 & 0 & 8.78 \\
\hline Ca2-NaAlP-F4 & 1.73 & 19.83 & 15.81 & 15.51 & 4.06 & 0.10 & 39.69 & 0.25 & 15.99 & 0 & 0 & 8.73 \\
\hline
\end{tabular}

$\mathrm{P}-\mathrm{O}-\mathrm{P}$ is easily hydrolyzed, and results in the depolymerization of the glass network upon hydration through the formation of a terminal-OH group $[8,32]$. When $\mathrm{CaO}$ was added to the NaAlP matrix, the quantity of released $\mathrm{Na}$ and $\mathrm{K}$ decreased in an obvious manner, but $\mathrm{Sr}$ and $\mathrm{P}$ increased dramatically. Therefore, the NaAlP glasses were not appropriate to immobilize alkali fluorides owing to the high leaching rate of alkali ions.

The $\mathrm{pH}$ variations of the leachate can also determine the leaching resistance of the samples, with increased stability associated with small variation (the initial $\mathrm{pH}$ for all the samples was 7). It should be noted that the $\mathrm{pH}$ of the deionized water used in the PCT test ranged from 6.4 to 7.5 for the IP waste forms (Table 5) and from 8.4 to 10.5 for the $\mathrm{NaAlP}$ waste forms (Table 6), which ranges from 6.5 to 7 or 9 for the iron-phosphate waste forms and from $\sim 6$ to 10 or 11 for the borosilicate glasses in Ref. [31].

In practice, the performance of any candidate waste form on the PCT relative to that of the Department of Energy's benchmark has come to define whether or not it is "satisfactory." Data from SRL-202-G glass [33], salt-occluded zeolite [17], and FZ-1 [31] leaching tests conducted under similar conditions were also converted to leaching ability units. As shown in Table 7, the leaching abilities of the various components of the IP glass were lower than that of the borosilicate SRL-202-G glass and salt-occluded zeolite, and also lower than or comparable to the iron phosphate glass FZ-1.

\section{CONCLUSION}

The immobilization of alkali fluoride wastes by phosphate glasses was evaluated in this study. IP and NaAlP glasses were mixed with simulated waste and reacted in air at temperatures in the range of $950-1200^{\circ} \mathrm{C}$. A maximum of 40 mol\% loading of mixed alkali fluorides was added to glasses in the experiment. The crystallization tendency increased with the simulated non-radioactive waste concentration, and crystalline phases were observed for about $43.5 \mathrm{~mol} \%$ loading of alkali fluorides in IP glasses and $48.6 \mathrm{~mol} \%$ in NaAlP glasses. The PCT analysis conducted on these samples in distilled water indicated that the leaching resistance of the IP glasses is better than that of the NaAlP glasses. The IP waste forms exhibited good performance with high effective waste loading, low cost, and good stability. This study is of significance for the scientific management and safety disposal of radwastes from MSRs and contributes to their long-term sustainable development.

Table 7 Comparison of leaching abilities for IP glasses and other representative waste forms $\left(\mathrm{g} \mathrm{m}^{-2}\right)$

\begin{tabular}{ccccc}
\hline Element & IP-F3 & Borosilicate glass SRL-202-G $^{\mathrm{a}}$ & Salt-occluded zeolite $^{\mathrm{b}}$ & FZ-1 $^{\mathrm{c}}$ \\
$\mathrm{Li}$ & 0.27 & 2.03 & 0.84 & 0.13 \\
$\mathrm{Na}$ & 0.06 & 1.96 & 0.22 & ND $^{*}$ \\
$\mathrm{~K}$ & 0.02 & 1.54 & $\mathrm{NDL}$ & $\mathrm{N}$ \\
$\mathrm{Sr}$ & $\mathrm{BDL}^{\#}$ & $\mathrm{ND}$ & $\mathrm{ND}$ & \\
\hline
\end{tabular}

Test conditions: $90^{\circ} \mathrm{C}, 7$ days, deionized water as leachant. * Not determined. \# Below detection limit in leachate. a) Borosilicate glass SRL-202-G is a standard reference borosilicate glass used at the Savannah River Laboratory, Data from Shade et al. b) Salt-occluded zeolite is an aluminosilicate ceramic investigated by Argonne National Laboratory. $\mathrm{V} / \mathrm{m}=100 \mathrm{~mL} \mathrm{~g}^{-1}$. c) FZ-1 is an iron phosphate glass waste form made at the United Medical Resources $\left(18 \mathrm{Na}_{2} \mathrm{O} \cdot 26 \mathrm{Fe}_{2} \mathrm{O}_{3} \cdot 46 \mathrm{P}_{2} \mathrm{O}_{5} \cdot 10\right.$ other, wt.\%) and tested (PCT) at the Pacific Northwest National Laboratory. 
Received 13 January 2016; accepted 14 March 2016; published online 15 April 2016

1 Jiang M, Xu H, Dai Z. Advanced fission energy program-TMSR nuclear energy system. Bull Chinese Acad Sci, 2012, 27: 366-374

2 Cai B, Wang J, Sun L, et al. Experimental study and numerical optimization on a vane-type separator for bubble separation in TMSR Prog Nucl Energ, 2014, 74: 1-13

3 Peretz FJ. Identification and Evaluation of Alternatives for the Disposition of Fluoride Fuel and Flush Salts from the Molten Salt Reactor Experiment at Oak Ridge National Laboratory, Oak Ridge, Tennessee. MSRE Technical Report ORNL/ER-380, 1996, 109-122

4 Molten Salt Panel of the Committee on Remediation of Buried and Tank Wastes. Evaluation of the U. S. Department of Energy's Alternatives for the Removal and Disposition of Molten Salt Reactor Experiment Fluoride Salts. Washington DC: National Academies Press, 1997

5 Donald I, Metcalfe B, Taylor RJ. The immobilization of high level radioactive wastes using ceramics and glasses. J Mater Sci, 1997, 32: 5851-5887

6 Siwadamrongpong S, Koide M, Matusita K. Prediction of chloride solubility in $\mathrm{CaO}-\mathrm{Al}_{2} \mathrm{O}_{3}-\mathrm{SiO}_{2}$ glass systems. J Non-Cryst Solids, 2004, 347: 114-120

7 Hrma PR. Retention of halogens in waste glass. Technical Report PNNL-19361. Richland: Pacific Northwest National Laboratory, 2010

8 Donald IW, Metcalfe B, Fong SK, et al. A glass-encapsulated calcium phosphate wasteform for the immobilization of actinide-, fluoride-, and chloride-containing radioactive wastes from the pyrochemical reprocessing of plutonium metal. J Nucl Mater, 2007, 361: 78-93

9 Sengupta P. A review on immobilization of phosphate containing high level nuclear wastes within glass matrix-present status and future challenges. J Hazard Mater, 2012, 235: 17-28

10 Mesko M, Day D, Bunker B. Immobilization of $\mathrm{CsCl}$ and $\mathrm{SrF}$ in iron phosphate glass. Waste Manage, 2000, 20: 271-278

11 Siemer DD. Molten salt breeder reactor waste management. Nucl Technol, 2014, 185: 100-108

12 Siemer DD. Improving the integral fast reactor's proposed salt waste management system. Nucl Technol, 2012, 178: 341-352

13 Mukhamet-Galeyev AP, Magazina LO, Levin KA, et al. The interaction of Na-Al-P-glass (Cs, Sr-bearing) with water at elevated temperatures $\left(70-250^{\circ} \mathrm{C}\right)$. MRS Proceedings, 1994, 353: 79

14 Lavrinovich YG, Kormilitsyn M, Konovalov V, et al. Vitrification of chloride wastes in the pyroelectrochemical method of reprocessing irradiated nuclear fue. Atom Energ, 2003, 95: 781-785

15 ASTM C1285-14, Standard Test Methods for Determining Chemical Durability of Nuclear, Hazardous, and Mixed Waste Glasses and Multiphase Glass Ceramics: the Product Consistency Test (PCT). West Conshohocken: ASTM International, 2014

16 Scott CD, Carter WL. Preliminary Design Study of a Continuous Fluorination Vacuum Distillation System for Regenerating Fuel and Fertile Streams in a Molten Salt Breeder Reactor. Technical Report ORNL-3791. Oak Ridge: Oak Ridge National Laboratory, 1966

17 Lewis MA, Fischer DF, Smith LJ. Salt-occluded Zeolites as an immobilization matrix for chloride waste salt. J Am Ceram Soc, 1993, 76: 2826-2832
18 Zhang L, Brow RK. A Raman study of iron-phosphate crystalline compounds and glasses. J Am Ceram Soc, 2011, 94: 3123-3130

19 Bingham P, Hand R, Hannant O, et al. Effects of modifier additions on the thermal properties, chemical durability, oxidation state and structure of iron phosphate glasses. J Non-Cryst Solids, 2009, 355: 1526-1538

20 Milankovic M, Furic K, Day DE. Electrical conductivity and structural properties of cesium iron phosphate glasses: a potential host for vitrifying nuclear waste. MRS Procedings, 2000, 663: 153

21 Liang XF, Lai YM, Yin GF, Yang SY. Effect of $\mathrm{CeO}_{2}$ doped on the structure of phosphate calcium glass. Chinese J Inorg Chem, 2011, 27: 35-39 (In Chinese)

22 Hudgens JJ, Brow RK, Tallant DR, Martin SW. Raman spectroscopy study of the structure of lithium and sodium ultraphosphate glasses. J Non-Cryst Solids, 1998, 223: 21-31

23 Tiwari B, Pandey M, Sudarsan V, et al. Study of structural modification of sodium aluminophosphate glasses with $\mathrm{TiO}_{2}$ addition through Raman and NMR spectroscopy. Phys B, 2009, 404: 47-51

24 Kasuga T, Abe Y. Calcium phosphate invert glasses with soda and titania. J Non-Cryst Solids, 1999, 243: 70-74

25 Van Wazer JR. Phosphorus and Its Compounds. New York: Interscience Publishers, 1958

26 Liu H, Ma J, Gong J, Xu J. The structure and properties of $\mathrm{SnF}_{2}-\mathrm{SnO}$ $\mathrm{P}_{2} \mathrm{O}_{5}$ glasses. J Non-Cryst Solids, 2015, 419: 92-96

27 Christie J K, Ainsworth RI, De Leeuw NH. Ab initio molecular dynamics simulations of structural changes associated with the incorporation of fluorine in bioactive phosphate glasses. Biomaterials, 2014, 35: 6164-6171

28 EJ/1186-2005 Characterization of radioactive waste forms and packages. International Classification for Standards, 2005 (In chinese)

29 Day D, Wu Z, Ray C, Hrma P. Chemically durable iron phosphate glass wasteforms. J Non-Cryst Solids, 1998, 241: 1-12

30 Liao QL, Lin HY, Wang F, Pan SQ, Mu T. Effect of $\mathrm{Na}_{2} \mathrm{O} / \mathrm{Al}_{2} \mathrm{O}_{3}$ molar ratio on the structure and performances of borosilicate glass wasteforms for simulated high-level radioactive liquid waste. J Nucl Radiochem, 2014, 36: 235-240 (In Chinese)

31 Goel A, McCloy JS, Fox KM, et al. Structural analysis of some sodium and alumina rich high-level nuclear waste glasses. J Non-Cryst Solids, 2012, 358: 674-679

32 Donald I, Metcalfe B. Thermal properties and crystallization kinetics of a sodium aluminophosphate based glass. J Non-Cryst Solids, 2004, 348: 118-122

33 Jantzen CM. Evaluation of Experimental Factors that Influence the Application and Discrimination Capability of the Product Consistence Test. Westinghouse Savannah River Company, Savannah River Site, 1990

Acknowledgments This work was supported by the "Strategic Priority Research Program" of the Chinese Academy of Sciences (XD02005003).

Author contributions Sun Y, Xia X, and Qiao Y conceived the study. Sun Y performed the experiments with help from Liu X and Qian Z; Sun Y wrote the paper with support from Xia X and Bao L. All authors contributed to the general discussion.

Conflict of interest The authors declare that they have no conflict of interest. 

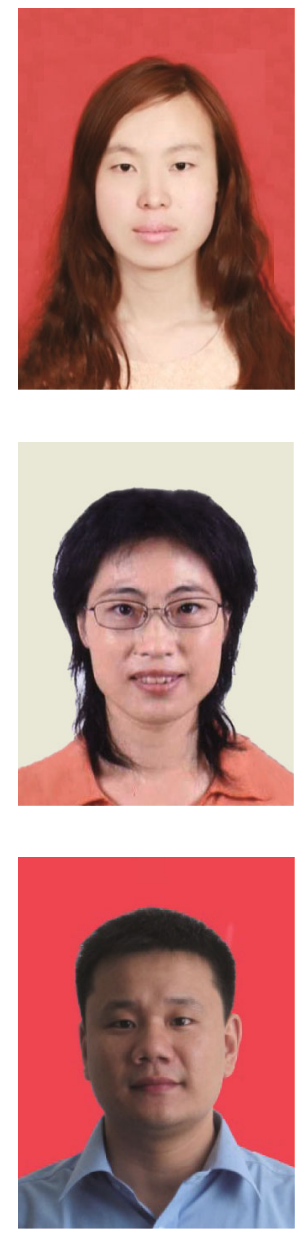

Yaping Sun received her BSc degree in nuclear chemical and nuclear fuel cycle from Lanzhou University in 2011. She is now a PhD candidate at Shanghai Institute of Applied Physics, Chinese Academy of Sciences. Her research is focused on the molten salt reactor radwastes disposal and vitrification of high level wastes.

Xiaobin Xia received her PhD degree from Japan's National Kyushu University in 2003. She later worked at Japan Atomic Energy Agency (JAEA) as PhD researcher and then moved to Nagoya University as a researcher. In 2007, she joined Shanghai Institute of Applied Physics, Chinese Academy of Sciences as a full professor and director of the Department of Nuclear Safety and Engineering, and Department of Technology Safety. Her current research focuses on radiation protection of high-energy particles, protection of medical radiation, security and nuclear energy system engineering of thorium base molten salt nuclear

Yanbo Qiao received his PhD degree from Shanghai Institute of Optics and Fine Mechanics, Chinese Academy of Sciences in 2009. He then worked as a postdoctoral fellow at the National Institute of Advanced Industrial Science and Technology (AIST), Japan. He joined Shanghai Institute of Applied Physics, Chinese Academy of Sciences in 2012. His current research interests include the management of radioactive wastes, molten salt reactor radwastes disposal and vitrification of high level wastes.

\section{模拟放射性氟化物废物的磷酸盐玻璃固化}

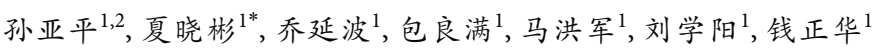

摘要 熔盐堆的运行和乏燃料的处理都不可避免地产生放射性氟化物废物. 不同于传统堆产生的氧化物废物, 这些氟化物废物大多以颗粒、 粉末等分散形式存在, 且具有腐蚀、化学稳定性差、易潮解等特点, 所以其处理处置有赖于新技术新工艺的研究. 本文分别选取铁磷酸盐 (IP)玻璃和钠铝磷酸盐(NaAlP)玻璃固化模拟碱金属氟化物, 并用X射线衍射分析、拉曼光谱和产品一致性检验方法对其结构和抗浸出性进 行了测试. 实验表明模拟氟化物在两种玻璃中的溶解度都很高 (40 mol\%以上), NaAlP玻璃固化体中碱金属浸出率较高, 这和其玻璃基材含有 较多的 $\mathrm{Na}$ 有关, 且拉曼光谱显示其结构中的磷氧四面体含有不稳定的 $Q^{3}$ 单元, 而IP玻璃固化体对所有元素的浸出率都低于 $1 \mathrm{~g} \mathrm{~m}^{-2} \mathrm{day}^{-1}$, 故 对固化熔盐堆产生的碱金属氟化盐有很大的潜在研究价值. 